\title{
Pedagogías contra el Despojo: Principios de una Eco/Demopedagogía Transformativa como Vehículo para la Justicia Social y Ambiental
}

\section{Pedagogies against Dispossession: Principles for a Transformative Eco/Demopedagogy as a Vehicle for Social and Environmental Justice}

\author{
Paul R. Carr * \\ Eloy Rivas \\ Nancy Molano \\ Gina Thésée \\ Universidad de Québec, Canadá
}

\begin{abstract}
Se analiza el contenido pedagógico de las luchas que las comunidades Zapatistas y las comunidades purépechas en México llevan a cabo contra del despojo y por la defensa de los territorios y el entorno ecológico. Se plantea que tales luchas de resistencia de los pueblos indígenas, en la medida que se orientan a la defensa del territorio y toda forma de vida que habita sobre éste, producen saberes y prácticas pedagógicas sobre los cuáles es posible construir, en los países del norte del mundo, una pedagogía transformativa que busque la protección de la vida a partir de formas de democracia densa y contra-hegemónica. El artículo discute una serie de principios que pueden orientar la práctica de una pedagogía crítica de corte ambientalista, democrática y emancipatoria, que aquí denominaremos eco/demopedagogía transformativa. Este artículo construye sobre los postulados teóricos de la pedagogía de la liberación latinoamericana y la pedagogía crítica norteamericana. Su base metodológica es la investigación documental y la observación etnográfica directa en las comunidades indígenas mencionadas.
\end{abstract}

Descriptores: América Latina; Grupo étnico; Ciencias de la educación; Justicia social; Ciencias ambientales.

This paper discusses the pedagogical implications of the struggles that the Zapatistas in Chiapas and the Purépecha communities in Mexico have been carrying out against dispossession and for the defense of the territories and the ecological environment. Such struggles, insofar as they focus on the defense of territories and all forms of life that dwell on it produce forms of pedagogical praxis from which we can learn and build, in the Global North, a form of transformative pedagogy aimed at stimulating the conscientization about and protection of all forms of life based on counter-hegemonic and transformative forms of democracy. The article discusses a set of principles that are meant to guide the development and practice of an environmental/ecological, democratic and emancipatory critical pedagogy, which we have labelled herein transformative eco/demopedagogy. This article builds upon the theoretical tradition developed by the Latin American liberation pedagogy and the North American critical pedagogy. Documentary research and direct ethnographic observation in the aforementioned indigenous communities constitute, likewise, the methodological basis of this article.

Keywords: Latin America; Ethnic group; Educational sciences; Social justice; Environmental sciences.

*Contacto: pcarr@gmail.com

ISSN: 2254-3139

www.rinace.net/riejs/

revistas.uam.es/riejs
Recibido: $\quad 3$ de noviembre 2017

$1^{\text {a }}$ Evaluación: 30 de diciembre 2017

$2^{\text {a }}$ Evaluación: 25 de enero 2018

Aceptado: 16 de febrero 2018 


\section{Introducción}

En América Latina, la consecución de la justicia social y la justicia ambiental forman parte de un proyecto histórico ancestral, pero inconcluso. Esto desde el punto de vista de los sectores sociales más afectados por los procesos de despojo y devastación ambiental y social a los que ha sido sometida esta región del continente americano durante los últimos quinientos años; a saber, los pueblos indígenas, así como las comunidades afrodescendientes y mestizas más empobrecidas (Alimonda, 2011a; Galafassi, 2012; Gilly y Roux, 2009; Leff, 2001, 2004, 2005). Un andamiaje de prácticas económicas, políticas y pedagógico-cognitivas que se sostienen sobre un modelo de apropiación social de la naturaleza de corte extractivista, así como sobre formas de colonialismo interno que se han implantado en esta región como parte de procesos más amplios de modernización capitalista, han hecho imposible la consecución de estas dos imbricadas formas de justicia (Alimonda, 2011b; Díaz-Polanco, 2005; González-Casanova, 2003a; Leff, 2005, 2006; Romero, 2011; Seoane, 2013a, 2013b; Seoane y Algranati, 2013a, 2013b).

Pero este conjunto hegemónico de prácticas económicas, políticas y pedagógicocognitivas de corte extractivista, ha encontrado diversas formas de resistencia entre las comunidades indígenas y afrodescendientes latinoamericanas (Arana, 2011; De Echave, Palacín y Pérez, 2011; González-Casanova, 2003b; Lamberti, 2011; Seoane, 2005, 2013b; Wagner y Giraud, 2011). Estas formas de resistencia, apoyadas en luchas pacíficas, tienen como fundamento la defensa del carácter común de territorios, la desmercantilización o emancipación de la flora, la fauna, el agua, la tierra respecto de la ley del valor de cambio, así como la defensa de formas de democracia profunda, densa y participativa (Leff, 2004; Seoane y Algranati, 2013b; Taddei, 2013a, 2013b). El argumento de este trabajo es que estas formas de resistencia indígena contra el despojo, en la medida que se orientan a, y se fundamentan en, la defensa del territorio y toda forma de vida que habita sobre el territorio, participan en la producción de saberes y prácticas pedagógicas de corte democrático y emancipatorio sobre los cuáles es posible construir, en el Norte del Mundo, una pedagogía transformativa orientada a la protección de la vida, la flora y la fauna, a partir de formas de democracia contra-hegemónica (Battiste, 2000; Carr y Abdi, 2013; Carr y Thésée, 2012). Esta forma de pedagogía que reconoce y adopta los saberes resultantes de las luchas de resistencia de los pueblos indígenas latinoamericanos la llamaremos aquí eco/demopedagogía transformativa.

Este trabajo se divide en tres partes. En la primera parte se describirán las formas en que los modelos hegemónicos de desarrollo en América Latina han participado en la devastación ambiental y social, reproduciendo formas de vulnerabilidad que impiden la consecución de la justicia ambiental y social. En la segunda parte definiremos las formas en que tales procesos de desposesión, que también adquieren el carácter de pedagogías de despojo, han sido contestados por las comunidades indígenas latinoamericanas en las que se identifica igualmente un componente pedagógico emancipatorio. En la última parte describiremos una serie de principios para el desarrollo de una eco/demopedagogía transformativa a partir del reconocimiento e incorporación de las lecciones pedagógicas que nos han legado las luchas contemporáneas en defensa de la tierra, los ecosistemas y los territorios de los pueblos indígenas en América Latina. Para finalizar, integramos estas reflexiones en un marco crítico que incluye cuatro campos de interés: el ambiente, las poblaciones marginalizadas, la justicia social y la democracia, conceptos que apuntalan lo que denominaremos la eco/demopedagogía transformativa. 


\section{Vulnerabilidad social y ambiental en América Latina}

Aunque a nivel mundial se han llevado a cabo esfuerzos por parte de diferentes actores de la sociedad para disminuir la pobreza y generar mejores condiciones sociales y ambientales, muchas poblaciones están lejos de vivir en el marco de condiciones sociales que les permita tener una vida con dignidad, seguridad social y ambiental (PNUD, 2016). De acuerdo con el Programa de las Naciones Unidas para el Desarrollo, en esta segunda década del siglo XXI un conjunto de desafíos sociales, tales como las desigualdades en el acceso a servicios de salud, a la educación, al reconocimiento y respeto de los derechos humanos, impiden que muchas poblaciones puedan tener acceso a un nivel mínimo de desarrollo humano (PNUD, 2016).

Debido a que la estructura de la marginalidad social actual ha sido configurada de acuerdo con los procesos históricos de acumulación del capital en el marco de las relaciones centroperiferia, la vulnerabilidad social está concentrada en los países del Sur Global y estratificada a nivel global de acuerdo con criterios étnicos, raciales, de edad y género. Los grupos indígenas, los migrantes racializados, las mujeres, los afrodescendientes, los adultos mayores y las minorías étnicas y sexuales constituyen los grupos sociales más vulnerados y expuestos a la inequidad social (figura 1). En Latinoamérica, los indígenas, las mujeres y las comunidades afrodescendientes tienen menor acceso a la escolaridad, con frecuencia son excluidos del mercado laboral (Anderson, 2004; CEPAL, 2000; Rangel, 2004; Sauma, 2004; Valenzuela y Rangel, 2004) y sometidos a la injusticia ambiental (Bullard, 1999; Rangel, 2004). En Ecuador, el 53\% de la población indígena tiene acceso a la educación primaria, $15 \%$ a la secundaria y solamente $1 \%$ a la universitaria. En Bolivia, la escolaridad es tres veces menor entre los grupos indígenas en comparación con la población mestiza y la diferencia es aún mayor con respecto de las poblaciones blancas. En Guatemala, solamente el 40\% de los indígenas sabe leer y escribir (Rangel, 2004; Sauma, 2004). De manera similar, según Sánchez y Franklin (como se citó en Rangel, 2004) en Ecuador y Perú las comunidades afrodescendientes presentan un índice de malnutrición elevado, así como niveles altos de mortalidad infantil y materna; el $79 \%$ de la población indígena vive en condiciones de pobreza y más del 50\% es indigente; el $26 \%$ está excluido del sistema educativo y el 33\% son analfabetos (Rangel, 2004). La marginalización de, y por, los modelos hegemónicos de desarrollo social, así como la exclusión respecto de bienes y derechos sociales fundamentales (tales como el trabajo, la educación, el medio ambiente sano y la salud) empujan a las personas a vivir en el aislamiento social o en condiciones de vulnerabilidad extremas (Barrientos, 2013; Blanchon, Moreau y Veyret, 2009). Esta estructura de marginalización social ha hecho también que estos millones de personas se vean obligadas a vivir en zonas geográficas donde priman la escasez alimentaria, la sequía y la vulnerabilidad ambiental (PNUD, 2016).

Lo anterior evidencia que las vulnerabilidades sociales, producidas por la exclusión y la marginalización social, están entrecruzadas con las vulnerabilidades ambientales. Ambas formas de vulnerabilidad se refuerzan mutuamente. Por estas razones, nosotros nos referimos a las vulnerabilidades ambientales como procesos sociales que tienen un carácter político; esto es, son fenómenos producidos por las desigualdades y las relaciones de poder que se configuran en contextos históricos y geográficos particulares. Son las poblaciones excluidas de, o desposeídas por, los modelos de desarrollo hegemónicos en un momento histórico determinado, así como por las políticas públicas implementadas por los gobiernos en congruencia con tales modelos de desarrollo (Sauvé 2014), las más expuestas 
y afectadas por situaciones de devastación ambiental que pudieron ser evitadas, por ejemplo, la guerra (Carr y Thésée, 2012), el saqueo de los bosques, el envenenamiento de la tierra y el pillaje neocolonial (figura 1).

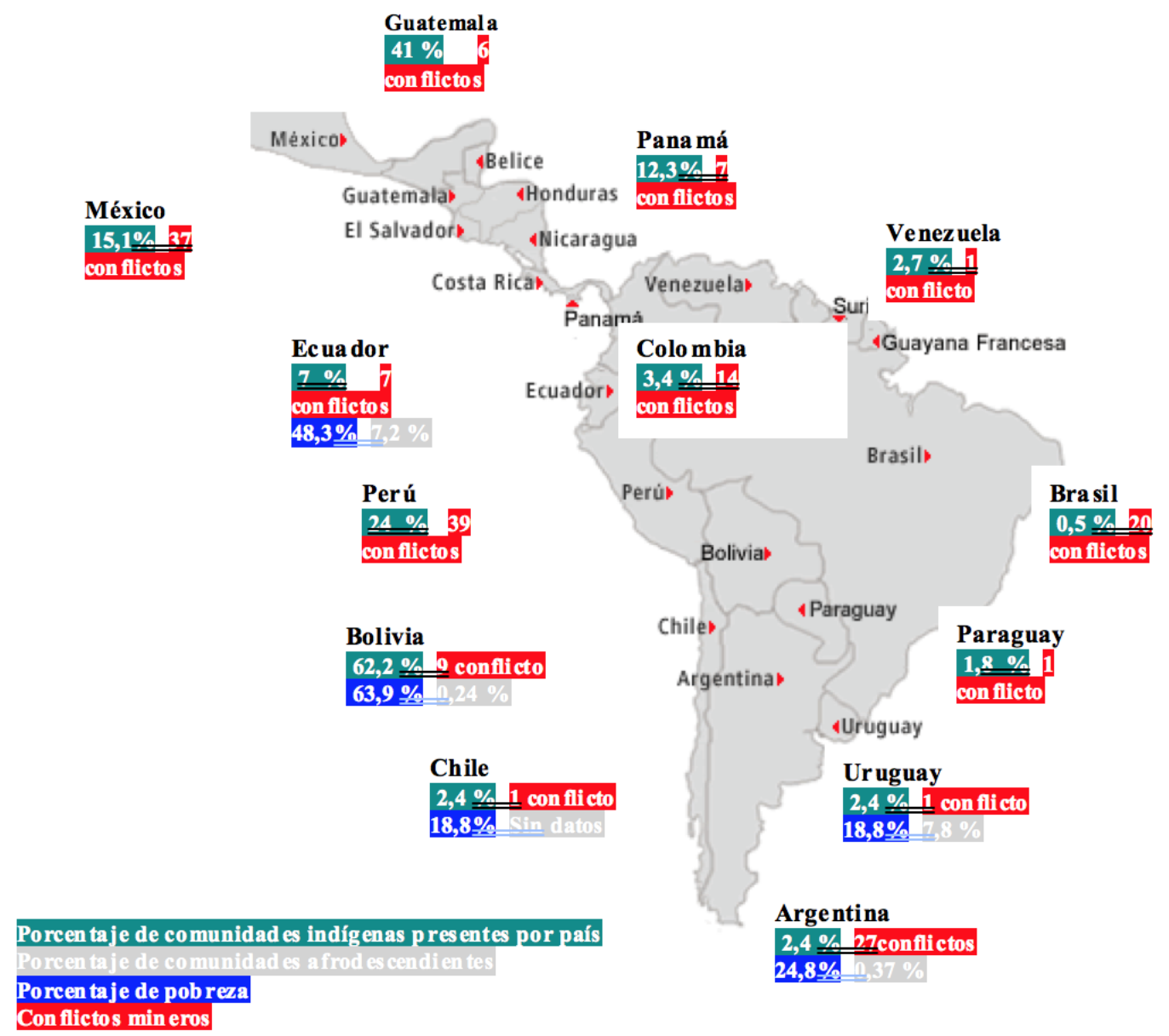

Figura 1. Geografía de la pobreza y los conflictos mineros en los países latinoamericanos con presencia indígena y afrodescendiente

Fuente: Recuperado de CEPAL (2014).

Debido a la existencia de este vínculo entre desigualdad, poder y vulnerabilidad social, el concepto de justicia ambiental que compartimos las y los autores de este trabajo parte del análisis de las condiciones sociales, económicas, políticas y culturales que participan de la producción social de las formas de devastación ambiental, así como de las formas diferenciadas en que tales procesos de vulnerabilidad ambiental afectan particulares poblaciones sociales (Blanchon, Moreau y Veyret, 2009; Schlosberg, 2013). En las páginas siguientes ofrecemos un panorama general de la forma en que los modelos de desarrollo en América Latina han contribuido a la producción de este vínculo entre vulnerabilidad social y devastación ambiental. 


\subsection{Despojo, degradación ambiental y social en América Latina}

En América latina, el vínculo entre vulnerabilidad social e injusticia ambiental al que nos hemos referido con anterioridad está ligado a los modelos hegemónicos de desarrollo, apropiación y dominación de la naturaleza - de extracción y mercantilización de los recursos naturales- que se han implantado históricamente en esta región, y que han afectado, sobre todo, a los pueblos indígenas, así como a las comunidades afrodescendientes (Carruthers, 2008; Leff, 2004; Roberts y Thanos, 2003). Tales modelos de desarrollo son, en primer lugar, el modelo de industrialización y modernización conocido como modelo de sustitución de importaciones y, en segundo lugar, el modelo neoliberal extractivista.

El modelo de sustitución de importaciones se puso en práctica durante el periodo que va de la tercera década del siglo Xx hasta finales de los años setenta. Aún en su diversidad, este modelo de industrialización tuvo como común denominador la puesta en práctica de una serie de políticas de crecimiento 'hacia adentro' que, buscando apuntalar la independencia de las naciones latinoamericanas con respecto de los países centrales del sistema mundo sobre la base del desarrollo de la industria local, sometieron a la naturaleza y sus 'recursos' a la ley del valor. En este modelo se entendía que el 'desarrollo' sólo sería posible por medio del apalancamiento de procesos de industrialización y acumulación apuntalados por una noción utilitarista de apropiación social de la naturaleza y su transformación en mercancías para el consumo interno y la exportación. Los estudios de la CEPAL durante esa época dan cuenta de los costos ambientales que tuvo la puesta en práctica de este modelo de desarrollo social (Sunkel y Gligo, 1980), mismo que llevó al agotamiento de reservas y recursos no renovables, a la tala intensiva de bosques, al uso extensivo de petróleo y otros contaminantes, al uso de técnicas de agricultura intensiva, a la sobre utilización y erosión de suelos, al uso de fertilizantes nocivos para el medio ambiente y al desplazamiento masivo de poblaciones de zonas rurales a zonas urbanas (Gligo, 2006; Prebisch, 1980; Sunkel, 1980, 1990).

El segundo modelo hegemónico de desarrollo, que conocemos como el modelo neoliberal, se inauguró en América Latina en 1973 a través de la dictadura de Augusto Pinochet en Chile. Es un modelo que se impuso por medio de la guerra y se consolidó sobre la base de la opresión social y la devastación ambiental (Alimonda, 2011b; Harvey, 2005a, 2005b; Klein, 2007). Un conjunto de cambios en la estructura legal de la sociedad chilena llevados a cabo durante la dictadura de Augusto Pinochet definieron y pusieron en práctica la relación fundamental que se establece desde entonces en américa latina, con muy escasas excepciones, entre el mercado, el estado, el medio ambiente y el capital privado. Desde entonces, la tierra, el agua, la flora y la fauna son sometidas a procesos de privatización y mercantilización por parte de empresas privadas, principalmente provenientes de los países centrales del sistema mundo, con el apoyo decisivo de los gobiernos locales. En el modelo neoliberal, los ecosistemas, la tierra y el agua, mismos que se entendían durante el modelo de sustitución de importaciones como propiedad nacional o propiedad común, son ahora transferidos a empresas privadas para garantizar la gestión, administración y explotación al servicio de las necesidades del mercado y la acumulación del capital. Por ejemplo, el Decreto Ley $\mathrm{N}^{\circ} 701$ para la forestación que se introdujo durante la dictadura de Augusto Pinochet fue el primero en américa latina que estableció subsidios para las empresas privadas. Esto dio origen a la apropiación del bosque por parte de empresas privadas y a la alteración de los ecosistemas, pues la forestación implicó la destrucción de bosque nativo y la sustitución por árboles rentables para la producción de madera y 
materiales derivados de la madera, como el pino y el eucaliptus. De igual forma, el Código de Aguas privatizó y permitió la apropiación del agua de por vida, separándolo de la propiedad de la tierra. Las actividades pesqueras, en el mismo espíritu, fueron desreguladas y entregadas a empresas privadas casi sin ningún tipo de limitación para su explotación (Arellano, 2013; Bauer, 1998; González, 2017).

Este modelo de privatización y sometimiento de los ecosistemas a los procesos de mercantilización y comercialización se extendió de forma gradual por el resto de América Latina a principios de los años ochenta. El neoliberalismo ha llevado al desarrollo de formas agresivas de apropiación social de la naturaleza y devastación ambiental. Aunque existen diferencias de acuerdo con el país y la región de la que hablemos, el modelo neoliberal extractivista ha implicado la radicalización de las condiciones que exacerban la injusticia social y acentúan las crisis ambientales. La puesta en práctica de diversas formas de acumulación por despojo, como el profesor David Harvey (2003) ha teorizado, ha implicado la privatización gradual, parcial o total de bienes comunes (como la tierra), la privatización y comercialización de bosques y selvas, agua dulce y animales, así como a la privatización de semillas, anteriormente de propiedad universal, por medio del establecimiento de patentes por parte de empresas privadas.

Además de que este modelo ha sometido la naturaleza a tales procesos de mercantilización -generando también despojo y desplazamiento territorial, pobreza y desigualdades sociales- ha dado pie a la emergencia de lo que se denomina neo-extractivismo (Gudynas, 2009). Este modelo se caracteriza por facilitar a las empresas privadas, principalmente provenientes de los países más ricos del sistema mundo (como los Estados Unidos, Canadá, China) la extracción extensiva de petróleo, oro, cobre, gas natural y otras fuentes de energía fósil, así como la explotación de recursos no renovables por medio de técnicas altamente destructivas del medio ambiente y nocivas para la salud humana, tales como la fracturación hidráulica (llamada comúnmente fracking) y la minería a cielo abierto. El neoextractivismo también implica la puesta en marcha de procesos industriales que someten a las y los trabajadores y las poblaciones locales a enfermedades derivadas de la exposición prolongada al cianuro, ácido sulfúrico y otros químicos que se usan para la extracción de minerales. Este modelo incentiva, además, el incremento de la desigualdad social, pues sólo una magra proporción de trabajadores de las comunidades locales son incorporados a tales procesos de producción. También acentúa los conflictos y las divisiones entre las comunidades locales, y provoca el desplazamiento de comunidades indígenas de sus tierras ancestrales (CIDE-GTMDHAL, 2014; MiningWatch Canada, 2013)

\section{Neoliberalismo, extractivismo cognitivo y pedagogías del despojo}

Estas formas de apropiación, extracción, dominación y expoliación de la naturaleza en función de criterios dictados por valor de cambio y el mercado no se sostienen solamente sobre una racionalidad y una visión del progreso y el desarrollo de corte tecnocrática y economicista. También se sostienen sobre un modelo epistemológico neocolonial y utilitarista que la académica y artista indígena Leanne Betasamosake Simpson en Canadá han tenido a bien llamar extractivismo cognitivo (Simpson y Klein, 2013); esto es, un modelo epistemológico antropocéntrico (y androcéntrico) que concibe a la tierra y la naturaleza, incluidas el agua, la flora y la fauna, como un 'recurso' externo a los humanos que está allí para ser extraído, poseído, dominado y comercializado en el marco de relaciones neo-coloniales y mercantilistas, en beneficio de sus propietarios y puesto a disposición de las demandas del mercado y la acumulación del capital. 
Incrustado en las representaciones mentales del sentido común y del saber científico, y cristalizado en la forma de prácticas sociales y políticas públicas, el extractivismo cognitivo tiende a adquirir un carácter hegemónico en el sentido gramsciano del término (Gramsci, 1971). Esto es, tiende a configurar un liderazgo moral, político y económico en el mundo social, el cual se impone tanto por medio del consenso como por la fuerza. En ese sentido, en su estatus de idea y práctica social hegemónica, el extractivismo cognitivo tiende a convertirse también en un modelo pedagógico; esto es, en un conjunto de creencias y prácticas fundadas en un modelo de conocimiento que asumen de manera acrítica, y legitiman por medio de la práctica, una noción netamente utilitarista de la naturaleza. En esta visión hegemónica, la naturaleza es imaginada como un recurso a ser apropiado, administrado, explotado y comercializado de forma agresiva y por medio de la violencia. Teniendo como derrotero este modelo cognitivo-pedagógico extractivista, vastas zonas naturales antes de propiedad común han sido privatizadas para la extracción de recursos minerales, y sus comunidades expulsadas, forzadas al éxodo o expuestas a las consecuencias socioecológicas catastróficas que tales proyectos producen.

Las empresas mineras canadienses, por ejemplo, han instalado en México (tanto que en varios países de América Latina), desde los años 90, una serie de proyectos de extracción de oro, cobre y plata que provocan enfermedades, inducen el desplazamiento forzado de las poblaciones indígenas, y estimulan el crecimiento del crimen organizado y redes de corrupción. Desde la firma del tratado del libre comercio entre Estados Unidos, México y Canadá (TLCAN), empresas como New Gold, Torex Gold Resources, Minera San Xavier, Blackfire Yamaha Gold, Resources Metallica, entre otras, han instalado proyectos de minería a cielo abierto en territorios de comunidades indígenas de Chiapas, San Luis Potosí, Oaxaca y Guerrero. En tan sólo dos décadas de operación, estas empresas han dejado a su paso zonas geográficas enteras devastadas, ríos contaminados, flora y fauna envenenada, así como poblaciones desérticas, sin gente (Bellota, 2017; CIDE-GTMDHAL 2014; MiningWatch Canadá, 2015). Tales empresas también han sido vinculadas, en conjunto con grupos paramilitares y gobiernos locales, con la represión, asesinato o la desaparición de activistas indígenas locales que se oponen a la puesta en práctica de tales proyectos (MiningWatch Canadá, 2013). Prácticas como las descritas se han expandido a todas las regiones del continente. Y su existencia ha sido facilitada por la confluencia de esta suerte de estado mental colonizador que es el extractivismo cognitivo del que nos habla Leanne Betasamosake Simpson, y las demandas del mercado capitalista mundial.

Estas prácticas extractivistas, ligadas a las llamadas economías de enclave, en la medida que están destinadas a la satisfacción de las demandas de los mercados mundiales liderados principalmente por los países centrales del sistema mundo, facilitan la emergencia de lo que se ha denominado nuevo imperialismo (Harvey, 2003), por guardar similaridades con los procesos de híper extracción y pillaje de recursos naturales a los que fueron sometidos los países de América Latina y los países de la periferia durante la época de la colonización y el esclavismo en los siglos XIV y XV, con consecuencias ambientales parecidas (Braudel, 1986).

Pero este andamiaje de saberes y prácticas económicas y cognitivas de corte extractivista han encontrado diversas formas de resistencia entre las comunidades que poseen prácticas y epistemologías diferentes sobre la naturaleza: a saber, las comunidades indígenas y afrodescendientes (Arana, 2011; De Echave, Palacín y Pérez, 2011; Fernández y Sepúlveda, 2014; González-Casanova, 2003b; Lamberti, 2011; Tabra y Aste, 2011; Wagner y Giraud, 2011). El argumento de este artículo es que tales prácticas de 
resistencia contra el despojo y por la protección del mundo natural contienen una importante gama de saberes pedagógicos sobre los cuáles podemos elaborar en los países del Norte Global una pedagogía transformadora de corte ambientalista y democrática.

En las páginas que vienen ofrecemos un panorama general de algunas de estas luchas sociales y epistemológicas de resistencia, tomando como ejemplo dos casos particulares (las comunidades indígenas de Cherán, México y las comunidades indígenas Zapatistas en México). Después de ello, llevaremos a cabo un proceso de reconocimiento de las lecciones pedagógicas que pueden ser extraídas de tales luchas. Basado en tales ejemplos, este artículo enumera una serie de principios que pueden servir de guía para el desarrollo de una práctica pedagógica democrática -aquí denominada eco/demopedagogía transformativa- que pueda participar de las luchas materiales y cognitivas de resistencia al despojo; un trabajo educativo que favorezca la transmisión de saberes y formas amorosas, democráticas, humanistas y respetuosas de habitar en el mundo.

\section{Lecciones eco-pedagógicas desde abajo}

Primero describiremos el caso de la comunidad indígena de Cherán, México. Enseguida describiremos y analizaremos el caso de las comunidades indígenas zapatistas.

\subsection{El ejemplo de Cherán, México}

Cherán es una comunidad de población mayoritariamente indígena (purépecha) ubicada en las montañas del Estado de Michoacán, México, una de las regiones más afectadas por el narcotráfico. Desde principios de la década pasada, esta comunidad fue víctima de un grupo de talamontes ligados con el narcotráfico cuya actividad principal consistía en devastar el bosque ubicado en esa región por medio de la tala inmoderada y clandestina de árboles para su comercialización en el mercado negro regional. Extensas zonas del bosque fueron destruidas y quemadas, y muchas personas locales asesinadas, bajo la mirada silenciosa de autoridades locales, estatales y federales que nunca hicieron nada para proteger el bosque y los habitantes del pueblo de Cherán. En 2010, como producto de la iniciativa de un grupo de mujeres indígenas locales, el pueblo dejó de solicitar intervención del gobierno y organizó una rebelión masiva contra los talamontes y narcotraficantes, quienes fueron expulsados por la fuerza. Cansados del abandono institucional del que fueron objeto, las y los habitantes del pueblo de Cherán también expulsaron a los políticos locales y comenzaron a reorganizar su vida política en el marco de las prácticas indígenas tradicionales, mismas que, en términos occidentales, se les puede denominar como prácticas de democracia directa. En el marco de esta forma de hacer la política, la comunidad está representada por una asamblea general, la cual se nutre de las decisiones tomadas por las asambleas barriales. Las decisiones tomadas en las asambleas barriales son llevadas ante la asamblea general donde son discutidas y, en su caso, adoptadas. Luego, estas decisiones se llevan ante el consejo de ancianos, máximo órgano de decisiones de la comunidad. Lo que el consejo de ancianos aprueba es luego ejecutado por las autoridades locales: comités barriales, ronda comunitaria, etcétera.

De acuerdo con la observación directa y la información recogida de primera mano por parte de Eloy Rivas, uno de los autores de este artículo, durante sus visitas a la comunidad por más de 4 años, la razón principal de la rebelión, de acuerdo con los miembros de la comunidad, fue la recuperación de la dignidad de la población local, la defensa del bosque y recursos naturales respecto del saqueo, así como el rescate de los valores indígenas para 
organizar la vida comunitaria, relacionarse con la naturaleza, distribuir la alimentación y organizar la educación y la seguridad comunitaria.

La organización comunitaria, la participación social, el trabajo colectivo, la cooperación y el respeto por los otros, así como las relaciones de cuidado del medio ambiente se enseñan no sólo en la escuela, sino también en actividades organizadas por la comunidad. El pueblo de Cherán también ha creado proyectos de conservación del bosque, así como de rescate de las medicinas tradicionales por medio del uso de plantas medicinales. Igualmente, a través de La memoria de la infamia, un museo que la comunidad ha creado en 2014, se enseña a los niños y niñas, y a los miembros más jóvenes de la comunidad, la infamia de la que fue objeto el bosque y la comunidad previo al ejercicio de su autonomía y su autogobierno. En congruencia con este proyecto pedagógico, el pueblo organiza además eventos nacionales e internacionales a través de los cuáles se discuten formas sustentables de vida basadas en el respeto a la comunidad, el uso de tecnologías para la generación de energía alternativa, como la energía solar, la seguridad alimentaria, y la práctica de saberes orientados al buen vivir en armonía y respeto hacia la naturaleza.

\subsection{El ejemplo de las comunidades Zapatistas en Chiapas, México}

El Zapatismo es considerado como el movimiento social que encabezó la primera rebelión contra el neoliberalismo en el mundo. Constituido y representado mayoritariamente por comunidades indígenas localizadas en las montañas de Chiapas, México, el movimiento zapatista tiene como objetivo primordial el desmantelamiento de los efectos negativos que las políticas neoliberales tienen sobre sobre el tejido social de las comunidades en México y en Latinoamérica. Una particularidad de este movimiento es que, a diferencia de otros movimientos sociales en Latinoamérica, su proyecto de emancipación y organización de la democracia se construye sobre la base de un proyecto de construcción de autonomía que implica, entre otras cosas, la desmercantilización, la administración colectiva y distribución equitativa de la tierra y de los bienes producidos socialmente, así como el cuidado colectivo de la flora, el agua y la fauna. Igualmente, las comunidades Zapatistas han creado instituciones autónomas de gobierno que entienden la democracia como un proceso social de organización de la paz social, misma que, de acuerdo con sus valores, sólo puede alcanzarse mediante la práctica de la igualdad material, de género, étnica y de clase (Baronnet, 2011a y 2011b; Cuevas, 2007; EZLN, 2015a, 2015c y 2015d; GonzálezCasanova, 2003b). Los principios políticos que rigen a las comunidades Zapatistas, mismas que están organizadas por medio de municipios que se denominan Caracoles y Juntas de Buen Gobierno, son los siguientes: 1) Servir y no servirse, 2) Representar y no suplantar, 3) Construir y no destruir, 4) Obedecer y no mandar, 5) Proponer y no imponer, 6) Convencer y no vencer, así como 7) Bajar y no subir (EZLN, 2015b). Estos principios de democracia, que ellos llaman 'desde abajo', sirven de guía ética para la participación pública entre las y los representantes populares y el público en general. Tales principios se han difundido y practicado durante más de dos décadas a través de la implementación de programas de educación popular que las comunidades denominan Educación Autónoma Zapatista (Baronnet, 2011b; EZLN, 2015a, 2015b, 2015c).

La Educación Autónoma Zapatista se basa en la elaboración y puesta en práctica de modelos curriculares que son diseñados por las comunidades mismas, a partir de procesos de participación activa. A través de tales procesos de participación colectiva se define cuáles son los saberes sociales, técnicos, éticos y políticos que la comunidad necesita para poder cumplir con el proyecto político de democracia indígena de acuerdo con los siete 
principios Zapatistas. De la misma forma, en tales procesos de construcción colectiva de modelos curriculares se define cuáles son los saberes que deben ser inculcados entre las y los estudiantes para cumplir con el proyecto social más amplio que busca garantizar la consecución de una forma de vida mejor, más libre y más democrática. Tales procesos colectivos, como ha definido Bruno Baronnet (2014, 201 1b), no sólo han logrado aumentar el nivel de conocimientos técnicos de las y los niños y adultos que han sido educados bajo las formas de democracia educativa después de 1994, sino que también han producido nuevas subjetividades que ponen el respeto por la vida y la naturaleza por encima de los intereses individuales. También han generado formas de relación social entre los seres humanos, así como entre seres humanos, animales y medio ambiente, mismos que se caracterizan por la desmercantilización, así como por la práctica de la ternura, el cuidado mutuo y la búsqueda de relaciones igualitarias, democráticas y no utilitaristas.

De las experiencias educativas en Cherán y en las comunidades Zapatistas antes descritas podemos destacar cuatro características que pueden servir de ejemplo para la educación en materia de medio ambiente. La primera de las características es que la educación no sólo se lleva a cabo en las escuelas oficiales. Las personas aprenden en la escuela, pero también en las asambleas de barrio, en los proyectos y trabajos comunitarios, en los programas de radio comunitaria y en los museos comunitarios diseñados para tal fin. Es decir, la sociedad toda y sus actividades colectivas representan espacios pedagógicos para los indígenas cheranenses y Zapatistas. Allí se construyen y reproducen conocimientos holísticos que implican el reconocimiento de que el ser humano, las plantas, los animales, el agua y la tierra son parte de una red de relaciones basadas en la interdependencia. La segunda de las características de este tipo de educación es que ésta se nutre, a la manera que enseñaba Paulo Freire (2009 y 1992), de la praxis; una praxis que rescata los saberes ancestrales que habían sido subyugados por la racionalidad productivista y extractivista moderna. Este conjunto de saberes respetuosos de la naturaleza tiende a colocar en el centro de las necesidades colectivas el cuidado y la protección de la vida humana, así como de todos los otros elementos naturales y espirituales que sostienen la vida. La tercera de las características de la educación en Cherán y la Educación Autónoma Zapatista consiste en que los saberes que se construyen con las y los niños a través de los procesos educativos no desconocen el valor del conocimiento científico, ni ponen en contraposición saberes tradicionales y saberes científicos. Tanto en la comunidad de Cherán como entre las comunidades Zapatistas, los saberes indígenas tradicionales y los saberes técnicos y científicos modernos se ven como dos formas, a menudo compatibles, de concebir el mundo y de darle sentido, lo que aporta a una noción más amplia del ser, del estar y del hacer parte de la naturaleza. Por ejemplo, los saberes sobre plantas medicinales se ven no siempre como sustitutos, sino como complementos de los saberes médicos modernos. Finalmente, la cuarta de las características que queremos destacar es que la educación en tales comunidades se concibe como un saber y un derecho común. Como tal, la educación no puede ser vendida, privatizada ni apropiada para beneficio de unos pocos, así como tampoco pueden ser privatizadas ni vendidas para beneficio personal las tierras comunales, el bosque, el agua, y todos los demás elementos del entorno natural y social.

En suma, la desmercantilización de la naturaleza, incluidos los humanos y animales, forma parte de los procesos de democratización del mundo de la vida que se han puesto en marcha en las comunidades mencionadas por medio de la educación escolar formal, no formal, así como por medio de la organización comunitaria autónoma dentro y fuera de las aulas escolares. 


\section{Principios para una eco/demopedagogía transformativa}

Las y los protagonistas de estas luchas sociales han producido formas de relaciones sociales a partir de las cuáles se pueden reconocer importantes lecciones pedagógicas. En primer lugar, es importante destacar que los procesos de enseñanza y aprendizaje se llevan a cabo a través de la incorporación de las necesidades específicas que tiene y define la comunidad. Por lo tanto, se les puede denominar como formas de educación contextualizada que se conciben con y para la comunidad. Para estas comunidades, el reconocimiento de la pertenencia de los individuos al mundo natural, la relación entre mundo social y mundo natural, así como la responsabilidad colectiva del uso, cuidado y defensa de la tierra y el entorno ecológico se reconocen como fundamentales (Baronnet, 2011a, 2014; Cuevas, 2007; McLaren, 2013).

En segundo lugar, la educación en estas comunidades se concibe también como un proceso de enseñanza y aprendizaje que integra las diferentes dimensiones espacio-temporales del contexto de la comunidad. Es decir, se conciben como espacios educativos no solamente las aulas escolares, sino también cualquier otra actividad pública organizada por y para la comunidad. Considerados así, estos espacios y momentos de construcción de conocimiento colectivo fortalecen también la construcción y el ejercicio de la democracia comunitaria, pues por medio de los mismos las personas y el público en general, no sólo las y los educadores, tienen la posibilidad de involucrarse de manera activa en la toma de decisiones de su comunidad y participar a su vez en nuevas maneras de construir formas de poder popular de corte democrático que combinan elementos micro y macro (GonzálezCasanova, 2003b). Asimismo, estos tipos de educación que fueron descritas deconstruyen y reconstruyen nuevas formas de relación ser humano- naturaleza, nuevas formas de habitar el territorio y de aprender a vivir juntos (De Souza Silva, 2013).

Vale destacar además que, en la medida en que tales prácticas educativas se llevan a cabo a través de una praxis que se nutre de nociones de igualdad y democracia, y que busca la consolidación de la paz, esta práctica educativa tiene fines transformativos o emancipatorios (Baronnet, 2011a; González-Casanova, 2003b). Además, como la consolidación de la paz se entiende como un proceso que se logra a través de la práctica de la igualdad, la democracia y la desmercantilización de la naturaleza, así como su cuidado, tal praxis educativa tiene un carácter holístico o 'verde', como han denominado en el norte del mundo destacados teóricos de la corriente pedagógica que se denomina green pedagogy, para utilizar la expresión de Kahn (2010), o revolutionary ecopedagogy como la ha denominado Peter McLaren (2013).

Las formas pedagógicas indígenas tanto en la comunidad de Cherán como en las comunidades Zapatistas se basan también en una noción del mundo social y natural que establece una ruptura epistemológica con respecto de la racionalidad instrumental moderna. Como sabemos, en la racionalidad científica moderna el mundo social se representa como separado del mundo natural. De igual forma, en el ser humano es imaginado, en tanto que ente dotado de capacidades racionales, como un ente separado del mundo natural: la flora, la fauna, el agua, la tierra. Por el contrario, en las cosmovisiones indígenas Zapatista y purépecha, en concordancia con otras naciones indígenas, por ejemplo, en Canadá, el ser humano es imaginado como parte integral del mundo natural, junto con los animales, las plantas el agua y la tierra. El mundo social se imagina como 
parte del mundo natural, y viceversa. Esto es cualitativamente diferente de la racionalidad instrumental occidental moderna, misma que imagina al ser humano como un ser separado de la naturaleza, y cuya facultad reside en su capacidad de adueñarse de la naturaleza y sus creaciones, así como de dominarlas y ponerlas a su servicio, como bien definieron los teóricos de la Escuela de Frankfurth (Cook, 2011; Horkheimer, 2004; Horkheimer y Adorno 2002; Nelson, 2011). En suma, esta serie de saberes y prácticas pedagógicas de resistencia al despojo, que incluyen la defensa del carácter común de la naturaleza en el marco de una visión holística de la misma, guardan una similitud con los saberes pedagógicos críticos que se desglosan en el marco de la pedagogía verde o ecopedagogía en el norte del mundo. Aunque, en la medida en que tales prácticas pedagógicas están basadas en nociones de democracia profunda, a los principios que se extraerán de estas luchas indígenas los denominaremos principios de eco/demopedagogía transformativa; esto es, una pedagogía ambientalista, democrática y orientada al cambio social.

Los principios pedagógicos que en las páginas siguientes desarrollamos de forma muy humilde y sin pretensiones totalizantes se inspiran en algunos de los principios y prácticas humanistas de las luchas sociales que fueron descritas en párrafos anteriores. Tales principios buscan estimular la reflexión sobre prácticas pedagógicas que, sostenidas sobre el ejercicio de la democracia, busquen la formación de sensibilidades humanas que sean capaces de cultivar la paz, así como cuidar la vida humana y el entorno natural. Los principios a los que se refiere la eco/demopedagogía transformativa son los siguientes:

a) La educación debería tener como objetivo la formación de ciudadanos libres, autónomos, reflexivos, informados y comprometidos con el cuidado de la naturaleza, la vida, así como con todo lo que apuntala la vida.

b) La educación debería basarse en una forma de praxis pedagógica transformadora y democrática que se lleve a cabo tanto en ambientes institucionales como informales, teniendo como derrotero un aprendizaje colectivo y comunitario.

c) La educación debería ser siempre una forma de ecopedagogía a la manera que la definió Freire en Pedagogía de la indignación (2012) y la han desarrollado Gutiérrez y Prado (1999), Moacir Gadotti (2000) y Richard Kahn (2010). Esto quiere decir que la educación debe buscar el florecimiento de principios éticos fundamentales que enseñen el amor y el respeto por la vida de los animales, los humanos, los ríos, los bosques. Al asumirse como ambientalista, la educación debe reconocer la dimensión ecológica (relación al mundo) de todo proyecto de desarrollo humano. Por tanto, el enfoque ecopedagógico deberá apuntalar prácticas sociales basadas en el respeto, la paz, la comunión y el amor.

d) La pedagogía debería cultivar la democracia en su forma más robusta o densa, no electoral. En esta medida, la pedagogía debe asentarse sobre los principios de la justicia social, la horizontalidad, la igualdad, el respeto entre todos los seres humanos, así como la igualdad de género, la concientización, la participación verdadera y la eliminación de toda forma de explotación, subordinación, maltrato, comercialización y abuso de todo ser humano. Igualmente, la educación debe ser guiada por principios antirracistas, anti-sexistas, promoviendo la igualdad racial, étnica y de acceso a los bienes comunes y los bienes socialmente producidos. 
e) La educación debería de ser una práctica descolonizadora y buscar la emancipación de los individuos, las comunidades y sus territorios. Así pues, la educación debe luchar contra las prácticas sociales que son la causa de la degradación ambiental, tales como las nuevas formas de colonización, extracción, privatización y mercantilización de bienes comunes. La educación, entonces, debe ser también una forma de pedagogía contra el despojo y el saqueo de recursos naturales de los países periféricos, así como el saqueo a las comunidades indígenas que habitan en tales territorios.

f) En la medida de que la educación es una práctica contra el despojo, la pedagogía debe definir como meta la práctica del amor, la comunión, la paz, el respeto, y el cuidado colectivo de la vida y los ecosistemas que sostienen la vida.

g) La educación debe privilegiar el diálogo, la deliberación y el entendimiento común entre los seres humanos. Y debe ser el principal mecanismo por medio del cual todo tipo de violencia, incluyendo la violencia estructural, sea desmantelada

h) La relación estudiante-maestro debe ser horizontal en el sentido que lo ha definido Paulo Freire (1992, 2009), y en el sentido que la definen las comunidades indígenas Zapatistas. La construcción de conocimiento y el reconocimiento de otros saberes debe ser el principio que guíe una educación basada en un paradigma emancipatorio.

i) La/el educador y la/el estudiante deben ser humildes. Esto quiere decir que en la práctica pedagógica-educativa se debe privilegiar el acto de vivir la vida, como dicen los indígenas Zapatistas, 'haciendo preguntas' (preguntando caminamos), no predicando verdades universales o dogmas.

Aunque consideramos estos principios como guías generales, es importante destacar que todo programa educativo siempre debe ser construido a partir de la experiencia, la necesidad y la realidad de cada comunidad. La eco/demopedagogía transformativa se concibe como un modelo (figura 2) que parte del reconocimiento de la complejidad en las relaciones socio ambientales y busca que la transformación apuntale la consolidación de la justicia social, la justicia ambiental y a la democracia. Desde este punto de vista, el modelo desarrolla las tres dimensiones que componen el concepto: la dimensión ecológica, la dimensión pedagógica y la dimensión democrática. A continuación, se definen cada una de ellas.

La dimensión ecológica hace referencia a la relación entre el mundo natural y el mundo social, a las dinámicas que allí se generan, así como al significado de ser y habitar en el territorio. Hace referencia también a la noción de pertenencia e interdependencia entre todos los seres vivos, y al reconocimiento de que tales redes de interdependencia se transforman por medio de la praxis cotidiana y toda intervención social en el entorno natural y ecológico. El ser humano, al tomar conciencia de que forma parte de la naturaleza, puede responsabilizarse y comprometerse en la defensa de su entorno, su territorio de vida, su historia, su presente y su futuro. Y puede involucrarse en la lucha contra todo aquello que amenace su entorno, principal fuente de vida: la inseguridad alimentaria, la enfermedad, la muerte, la desigualdad y la violencia. La dimensión ecológica, en este sentido, propone el cambio y la transformación positiva de la relación entre humanos y naturaleza, así como la relación entre todos los seres humanos. 


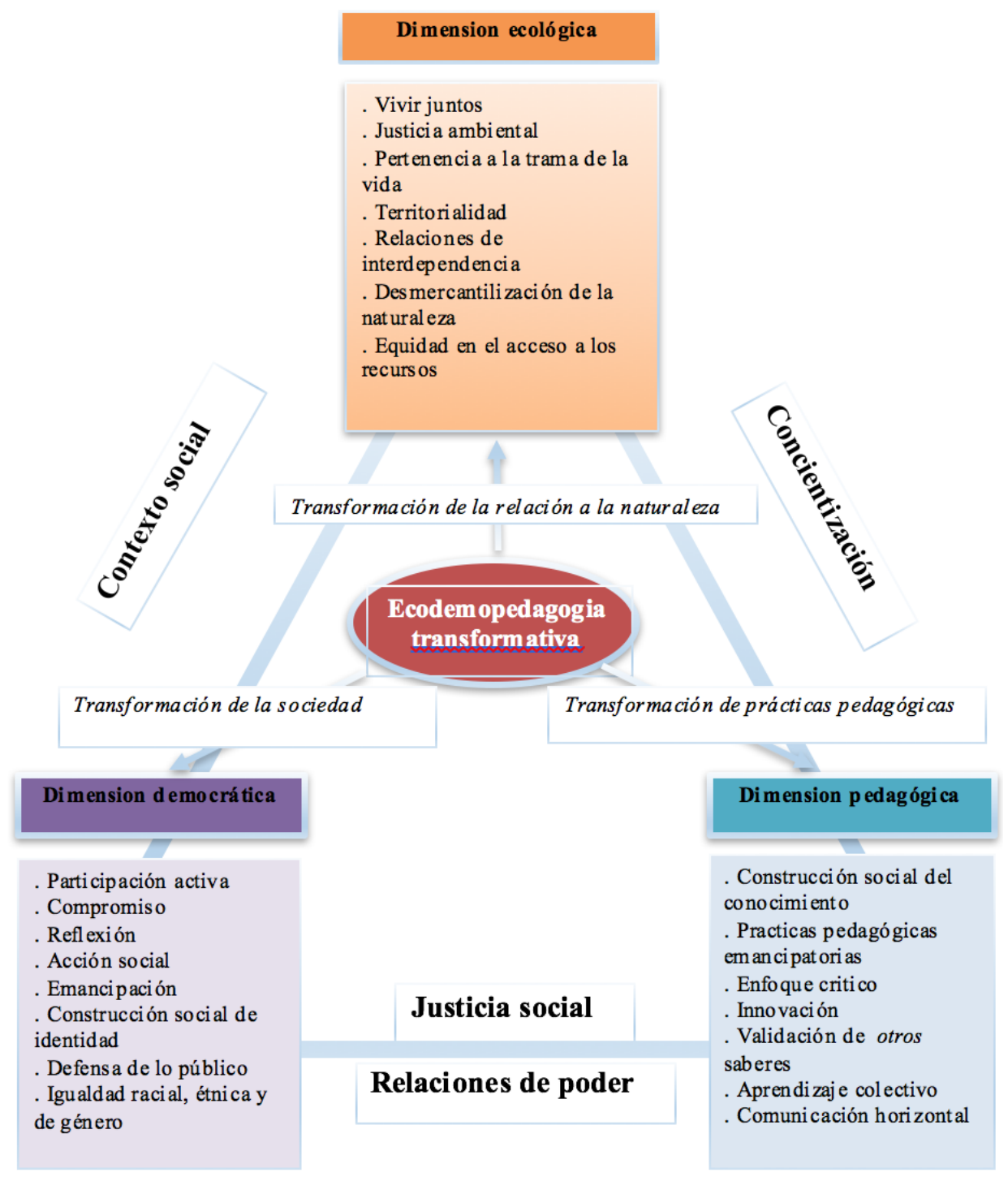

Figura 2. Modelo de Eco/demopedagogía transformativa

Fuente: Elaboración propia.

La dimensión pedagógica evoca transformaciones en las prácticas pedagógicas. Pero también va más allá, pues tales transformaciones se encuentran apuntaladas por un conjunto de representaciones que guían la acción educativa en favor de la consecución final y definitiva de la paz y la justicia social. Para ello, un enfoque socioconstructivista que considere los saberes construidos en otros escenarios diferentes al ámbito escolar y que son producto de la praxis de las comunidades es la base para la apropiación de lo que aquí hemos denominado eco/demopedagogía transformativa. La dimensión pedagógica también implica el establecimiento de prácticas innovadoras que rebasen los modelos tradicionales y que reconozcan el valor de aprender con otros, dentro y fuera de la escuela. Estas prácticas deben permitir a los actores educativos hacer parte de la interpretación, comprensión y forma de habitar el mundo de las comunidades, pues se entiende que esto puede permitir el fortalecimiento de su autonomía y autodeterminación para defender la vida en todas sus formas. 
Para que los elementos evocados en las dos dimensiones anteriores se articulen y tengan sentido en el contexto de las necesidades de las comunidades, la dimensión democrática aparece como un eje que completa el mecanismo que permite la transformación de la sociedad. Hablamos aquí de una democracia en la cual se promueve y se garantiza una participación ciudadana activa basada en la reflexión crítica que incite su implicación en la construcción y reconstrucción de la identidad individual y colectiva. Esto solamente será posible teniendo como base principios de equidad, no discriminación, de reconocimiento y de respeto por las y los otros, así como por el entorno ecológico. La figura 2 pretende representar el modelo que proponemos.

\section{La eco/demopedagogía transformativa en el contexto escolar}

En las líneas precedentes describimos procesos educativos de corte emancipatorio que surgen de un proyecto de praxis orientada a neutralizar el despojo extractivista y garantizar la paz con democracia y justicia social. Las luchas contra el despojo extractivista muestran el potencial movilizador y educativo de las comunidades, así como sus capacidades de autoformación, de recuperación de saberes y de gestación de procesos autónomos para recuperar aquello que les ha sido arrebatado durante años. Estas prácticas, como hemos mencionado, constituyen formas de educación fuera del aula escolar que tienen un impacto positivo sobre los miembros de la comunidad y sobre el tejido social en su conjunto. Aunque reconocemos la enorme importancia de tales prácticas educativas 'sin muros', vale la pena también reconocer que los procesos educativos que se gestan dentro de las aulas escolares en tales comunidades también aportan elementos al empoderamiento de las comunidades. La educación escolar es siempre una herramienta importante para el libre desarrollo de la autonomía, el aprendizaje colectivo en la praxis y la participación en la defensa del territorio y de un modo de vida consciente del valor de la naturaleza.

La educación escolar elaborada y aplicada de forma crítica puede ser un acto político (Cole, 2007; Lucio-Villegas, 2015; Thésée, Carr y Potwora, 2015), un dispositivo de emancipación y participación social (Lenoir et al., 2007), una herramienta para que las comunidades conjuguen su interpretación de la realidad y el mundo con el sentido de su ser-en el mundo y su relación a los otros seres humanos y al ambiente (Sauvé, 2007), así como un aporte a la construcción de identidad individual y colectiva que permita la transformación de la realidad (Sauvé, 2014). Por lo tanto, una educación escolar emancipatoria debe siempre incluir la enseñanza sobre el medio ambiente en sus dimensiones políticas y sociales (Thésée y Carr, 2008). Visto así, la escuela aparece como una vía para reflexionar, analizar y cuestionar las causas de las desigualdades y para encontrar acciones que permitan a las comunidades posicionarse en tanto que habitantes en interrelación con el medio ambiente y en defensa de la vida.

En función de lo anterior, podemos decir que la escuela también es un espacio privilegiado en el que los estudiantes aprenden a situarse en el mundo en relación a los otros y al ambiente, aprendizaje por medio del cual se pone en evidencia la necesidad de modificar dicha relación (Johnston, 2009) desde una perspectiva crítica y transformativa con el fin de contribuir a una educación emancipatoria que participe en la invención de una nueva visión de mundo y una nueva cultura (Lucio-Villegas, 2015; Jutras y Bertrand, 1998). Una 
educación escolar organizada de este modo ofrece la esperanza de contribuir a inventar otro futuro para el planeta (Collard-Fortin y Gauthier, 2014; Charland y Cyr, 2011). En ese sentido, para vehicular dichos procesos de formación y transformación a través de prácticas pedagógicas democráticas y transformativas que sean capaces de descolonizar la relación con el conocimiento y el ambiente (Thésée y Carr, 2008), mencionaremos algunos desafíos educativos desde diferentes dimensiones.

Empezaremos haciendo referencia al sentido mismo de la educación. Si se asume que la crisis global socio ambiental es también una crisis de la educación, es necesario por lo tanto revisar los fundamentos de ésta última. Para ello es necesario, entonces, preguntarse: ¿Cuál es el fin y la función social de la educación? ¿Cuáles son los principios que guían la acción educativa? ¿De qué manera aporta a la construcción de identidad individual y colectiva? ¿Cuál es el papel de la educación en las luchas de resistencia contra el despojo? ¿Es la educación un instrumento del modelo hegemónico de desarrollo? ¿ $\mathrm{O}$ es por el contrario un espacio para el análisis crítico y la acción comprometida para la transformación de la sociedad? Lo que planteamos nosotros es una educación transformativa que busque generar un cambio sustancial en el individuo y en la sociedad en su conjunto (Pickett, 2016), a través de la comprensión y transformación de sus constructos cognitivos. Esto implica la práctica de una educación crítica que considere la dimensión ecológica (la relación al mundo), epistemológica (la relación al conocimiento), relacional (la relación al otro) e identitaria (la relación a sí mismo) tanto entre los maestros como entre los estudiantes. Esto implica también la práctica de una educación a través de la cual la sociedad en su conjunto se implique en el reconocimiento de las desigualdades sociales y ambientales y haga frente a las mismas con acciones concretas que partan desde abajo y posicionen a las comunidades como generadoras de conocimiento válido.

La puesta en práctica de una educación crítica requiere que cuestionemos también los ambientes de enseñanza y de aprendizaje, las competencias que se privilegian en la escuela, las prácticas pedagógicas, los currículos y la formación inicial de maestros. Diversos autores (Herrera et al., 2006; Sauvé, 1997, 2014) consideran por ejemplo que los ambientes de enseñanza y de aprendizaje, en una visión tradicional, están caracterizados por la compartimentación disciplinar, la heteronomía de los estudiantes y el aislamiento de la escuela en relación a las realidades del medio social. Dichos factores no resultan favorables si se quiere llevar a cabo una educación tendiente a la transformación. Para llevar a cabo una educación transformadora se requieren currículos abiertos y flexibles que impulsen la crítica reflexiva de la democracia normativa, y que construya lazos con la sociedad civil de manera que los estudiantes comprendan el funcionamiento de la sociedad y participen en la transformación de la misma. Por tanto, se evidencia la necesidad de una transformación de la escuela tradicional, que destruya sus muros y que adopte la realidad del contexto y las urgencias socioambientales como la base para su quehacer formativo y emancipatorio en un proyecto de construcción de sociedad distinto e inclusivo; una sociedad, para utilizar el concepto zapatista, donde quepan muchos mundos y donde otros mundos sean imaginados como posibles. En consecuencia, se hace necesario repensar el sistema escuelasociedad y la manera en que éste reproduce de manera acrítica un sistema de valores hegemónico que deshumaniza y aumenta la distancia tanto entre los seres humanos como entre los seres humanos y la naturaleza.

También es pertinente cuestionarse sobre la concepción que tenemos del conocimiento, del saber, así como de la construcción y validación del conocimiento. ¿Qué conocimientos se privilegian en la escuela? ¿Qué tipo de saberes se validan y se favorecen? ¿Cómo se 
construye el conocimiento con los estudiantes? ¿Existen saberes que son excluidos de forma deliberada? Incluir estas preguntas en nuestros análisis sobre la educación permitiría hablar de la descolonización de saberes y motivaría al reconocimiento de epistemologías alter-nativas (Fernández y Sepúlveda, 2014; Thésée y Carr, 2008) que sean más inclusivas y que den voz a los grupos y comunidades que han sido excluidas. Este diálogo de saberes permite la construcción de identidad individual y colectiva que desemboca a su vez en participación ciudadana y acción colectiva. Esta formación ciudadana hace parte del enfoque político educación ambiental (Hursh, Henderson y Greenwood, 2015) ya que implica la conciencia de responsabilidad compartida frente a los sistemas de vida y a la toma de decisiones frente a las cuestiones socioecológicas (Sauvé, 2014).

Cuestionar la orientación positivista de la educación y la relación poder-conocimiento, permitirá considerar las consecuencias sociales de las decisiones y orientaciones educativas que parecen deseables (Bertrand y Valois, 1999). En consecuencia, hablamos de una educación enfocada a gestar transformaciones para construir sociedades más equitativas, más justas, más humanas, con una visión de mundo y una manera de habitarlo distintas. Para llegar a estas transformaciones, será también necesario adoptar la concepción densa de la democracia (Carr, 2008; Carr, Pluim y Thésée, 2014) que hace referencia al compromiso social enfocado a la emancipación social.

La emergencia de prácticas pedagógicas transformativas que aporten al debate y a las luchas de resistencia contra el despojo sólo es posible dentro de un marco de transformaciones estructurales del sistema educativo tradicional. Dichas transformaciones, aunque deben partir del reconocimiento de las condiciones que existen en cada contexto social en particular, deben reconocer, tal como hemos propuesto en este artículo, las importantes lecciones pedagógicas que las luchas sociales de los oprimidos, encabezadas por las naciones indígenas, están llevado a cabo contra el despojo, por la defensa de los territorios y por la protección y cuidado de toda forma de vida que habita sobre los territorios.

\section{Conclusiones}

Las luchas de resistencia de los pueblos indígenas que hemos descrito en este artículo aportan importantes lecciones pedagógicas que surgen de los procesos de defensa de los territorios. Estas lecciones se desprenden de una praxis que busca la desmercantilización de la naturaleza y apuntala el reconocimiento de la pertenencia del ser humano al entorno natural, así como de la relación fundamental entre el mundo social y el mundo natural (dimensión ecológica). Estas luchas también construyen nuevas formas de relaciones sociales basadas en la cooperación, deconstruyen las relaciones de poder, empoderan a las comunidades y fortalecen formas de democracia participativa en donde la igualdad racial, étnica y de género son la prioridad (dimensión democrática). Otra de las lecciones que nos son legadas por las luchas de los pueblos indígenas que han sido descritas están relacionadas con la implementación de unas prácticas pedagógicas contra-hegemónicas, innovadoras y emancipadoras a través de las cuales se reconocen los saberes tradicionales de las comunidades y se establecen diálogos que descolonizan y validan otras formas de ver e interpretar el mundo (dimensión pedagógica). Sobre la base del reconocimiento de este conjunto de saberes hemos expuesto una serie de principios que buscan guiar el desarrollo e implementación de saberes orientados a la protección y cuidado de la vida y 
de los ecosistemas que sostienen la vida. A este conjunto de valores para una pedagogía emancipatoria de corte ambientalista y democrática la hemos denominado eco/pedagogía transformativa.

Reconocemos que para que la eco/demopedagogía transformativa sea lleve a cabo es necesario que educadores y estudiantes participen también de la transformación de las estructuras sociales y las relaciones de poder que oprimen a las comunidades más vulnerables. También se debe participar en la construcción paulatina de relaciones sociales basadas en la equidad, la horizontalidad y el reconocimiento respetuoso del valor intrínseco que tienen las diversas identidades de personas y grupos sociales. Y también se debe participar en la defensa y protección de la naturaleza frente a los procesos extractivistas y de despojo a partir del desarrollo de una conciencia y una sensibilidad que tengan como fundamento el respeto de todos los seres humanos y sus entornos ambientales. Esto es lo que hemos pretendido reflejar en el modelo elaborado, mismo que integra cada una de las dimensiones que componen lo que hemos denominado la eco/demopedagogía transformativa. Esta forma pedagógica, que según nuestro modo de ver se encuentra presente en las luchas de las comunidades indígenas en América Latina, tiene la potencialidad de facilitar el ejercicio de una democracia robusta, densa y contrahegemónica no sólo en las sociedades mestizas latinoamericanas, sino también en el Norte del Mundo. Como práctica educativa, también puede servir como ejemplo a nivel individual entre las y los educadores que en el mundo entero están comprometidos con el fortalecimiento de los valores democráticos, críticos y emancipatorios. Para ello, la educación transformadora necesita cultivar no solamente la concientización social, sino también la potencialidad de los seres humanos para involucrarse en los procesos sociales que busquen la democracia y la consecución de la justicia social y ambiental.

La producción de saberes pedagógicos, desde John Dewey hasta Paulo Freire, incluyendo la escuela de pedagogía crítica, pasando por los rigurosos ejemplos con los que contamos hoy en día tanto en el norte como en el sur del mundo, se ha nutrido de proyectos colectivos de emancipación social. Por su parte, las prácticas de emancipación social que emergen de los movimientos contra la guerra, antirracista, anticolonial y anti patriarcal se han beneficiado también de los saberes pedagógicos críticos. Esta relación histórica, rica y dialéctica, está siendo amenazada por la colonización del saber pedagógico crítico del que están siendo objeto las universidades y otros espacios de producción científica, académica y educativa. En este contexto neoliberal, la pedagogía crítica y la praxis emancipatoria viven una presión por ser separadas, suprimidas de su relación holística y de crecimiento conjunto. Como un gesto de humilde resistencia, y en apego a los principios de la pedagogía crítica, recurrimos a las luchas de los más humildes sectores de la sociedad latinoamericana, para aprender de sus contenidos pedagógicos, repensar nuestra relación con el mundo y sus ecosistemas, y continuar cultivando el vínculo entre pensamiento y acción, nexo que ha probado ser fructífero para la construcción de sociedades sustentables, de paz, respeto y reconocimiento. Los principios de eco/demopedagogía que aquí se bosquejan buscan establecer ese puente entre la pedagogía y las luchas sociales, entre realidad y utopía, así como entre diferencia y comunión entre las luchas de los oprimidos y los saberes que buscan superar las opresiones.

\section{Referencias}


Alimonda, H. (2011a). La colonialidad de la naturaleza. Una aproximación a la ecología política latinoamericana. En H. Alimonda (Coord.), La naturaleza colonizada. Ecología política y minería en América Latina (pp. 21-58). Buenos Aires: CLACSO.

Alimonda, H. (2011b). Introducción. En H. Alimonda (Coord.), La naturaleza colonizada. Ecología política y minería en América Latina (pp. 11-20). Buenos Aires: CLACSO.

Anderson, J. (2004). Categorías de diferencia, trayectorias de desigualdad: Superar la pobreza femenina diversa en América Latina. En M. Valenzuela y M. Rangel (Eds.), Desigualdades entrecruzadas. Pobreza, género, etnia y raza en América Latina (pp. 87-137). Santiago de Chile: OIT.

Arana, M. (2011). Minería y territorio en el Perú: Conflictos, resistencias y propuestas en tiempos de globalización. En H. Alimonda (Coord.), La naturaleza colonizada. Ecología política y minería en América Latina (pp. 219-222). Buenos Aires: CLACSO.

Arellano, A. (2013). El millonario negocio del agua. Cómo se fraguó la insólita legislación que tiene a Chile al borde del colapso hídrico. Recuperado de: http://ciperchile.cl/2013/12/12/como-sefraguo-la-insolita-legislacion-que-tiene-a-chile-al-borde-del-colapso-hidrico/

Baronnet, B. (2011a). Autonomía educativa zapatista: Hacia una pedagogía de la liberación india en Chiapas. Em Aberto, 24(85), 127-144.

Baronnet, B. (2011b). La apuesta de las escuelas zapatistas de Chiapas por descolonizar la educación en los pueblos campesinos mayas. Decisio, 30(4), 39-43.

Baronnet, B. (2014). Desafiando la política del estado: Las estrategias educativas de los pueblos originarios en Colombia y México. Revista Pueblos y Fronteras Digital, 8(16), 126-156.

Barrientos, A. (2013). Does vulnerability create poverty traps? En A. Sheperd y J. Brunt (Eds.), Chronic poverty (pp. 85-111). Londres: Palgrave Macmillan.

Battiste, M. A. (2000). Reclaiming indigenous voice and vision. Vancouver: UBC Press.

Bertrand, Y. y Valois, P. (1999). Fondements eeducatifs pour une nouvelle societe. Lyon: Ed. Nouvelles AMS.

Bauer, C. J. (1998). Against the current: Privatization, water markets, and the state in Chile. Nueva York, NY: Springer.

Blanchon, D., Moreau, S. y Veyret, Y. (2009). Comprendre et construire la justice environnementale. Annales de Geographie, 118(665), 35-60.

Braudel, F. (1986). Civilization and capitalism, 15th-18th century, the wheels of commerce. Nueva York, NY: Perennial Library.

Bullard, R. D. (1999). Dismantling environmental racism in the USA. Local Environment, 4(1), 519.

Carr, P. R. (2008). Educating for democracy: With or without social justice. Teacher Education Quarterly, 35(4), 117-136.

Carr, P. R. y Abdi, A. A. (2013). Framing contemporary democracy and the potential for counterhegemonic possibilities. En A. Abdi y P. R. Carr (Eds.), Educating for democratic consciousness: Counter-hegemonic possibilities (pp. 1-13). Nueva York, NY: Peter Lang.

Carr, P. R. y Thésée, G. (2012). Lo intercultural, el ambiente y la democracia: Buscando la justicia social y la justicia ecológica. Visão Global, 15(2), 75-90.

Carr, P. R., Pluim, G. y Thésée, G. (2014). The role of education for democracy in linking social justice to the 'built' environment: The case of post-earthquake Haiti. Policy Futures in Education, 12(7), 933-944. 
Carruthers, D. (Ed.). (2008). Environmental justice in Latin America. Problems, promise and practice. Boston, MA: MIT Press.

CEPAL. (2000). Etnicidad, "raza" y equidad en América Latina y El Caribe. Recuperado de: http://repositorio.cepal.org/bitstream/handle/11362/31450/So08674_es.pdf?sequence= 2

CEPAL. (2014). Panorama social en América Latina. Recuperado de https://www.cepal.org/es/publicaciones/37626-panorama-social-america-latina-2014

Charland, P. y Cyr, S. (2011). Enjeux et défis liés à l'intégration des préoccupations environnementales en enseignement des sciences et de la technologie au secondaire au Québec. Formation et Profession: Bulletin du CRIFPE, 18(2), 18-21.

Cole, A. G. (2007). Expanding the field: Revisiting environmental education principles through multidisciplinary frameworks. The Journal of Environmental Education, 38(2), 35-45.

Collard-Fortin, U. y Gauthier, D. (2014). La communauté d'apprentissage professionnelle: outil l'appropriation des principes de l'éducation relative à l'environnement (ERE) et au développement durable (EDD) auprès d'enseignants du secondaire. Revue Internationale $d u$ CRIRES, 2(1), 8-25.

Cook, D. (2011). Adorno on nature. Durham: Routledge

Cuevas, J. H. (2007). Salud y autonomía: El caso Chiapas. Recuperado de http://www. who. int/social_determinants/resources/csdh_media/autonomy_mexico_2007_es

De Echave, J., Palacín, M. y Pérez, M. (2011). El escenario actual: Tendencias, desafíos y posibilidades. En H. Alimonda (Coord.), La naturaleza colonizada. Ecología política y minería en América Latina (pp. 235-253). Buenos Aires: CLACSO.

De Souza Silva, J. (2013). La pedagogía de la felicidad en una educación para la vida: El paradigma del "buen vivir"/"vivir bien" y la construcción pedagógica del 'día después del desarrollo.' En C. Walsh (Coord.), Pedagogías decoloniales: Prácticas insurgentes de resistir, (re)existir y (re)vivir (pp. 470-507). Quito: Abya Yala.

Díaz-Polanco, H. (2005). Etnofagia y multiculturalismo. Revista Memoria, 20(3), 5-12.

EZLN. (2015a).Gobierno autónomo I. Cuaderno de texto del primer grado del curso la libertad según l@s zapatistas. Chiapas: Ejército Zapatista de Liberación Nacional.

EZLN. (2015b). Gobierno autónomo II. Cuaderno de texto del primer grado del curso la libertad según l@s zapatistas. Chiapas: Ejército Zapatista de Liberación Nacional.

EZLN. (2015c).Resistencia autónoma. Cuaderno de texto del primer grado del curso la libertad según l@s Zapatistas. Chiapas: Ejército Zapatista de Liberación Nacional.

EZLN. (2015d). Participación de las mujeres en el gobierno autónomo. Cuaderno de texto del primer grado del cursola libertad según l@s Zapatistas. Chiapas: Ejército Zapatista de Liberación Nacional.

Fernández, B. S. y Sepúlveda, B. (2014). Pueblos indígenas, saberes y descolonización: Procesos interculturales en América Latina. Polis, 13(38), 7-15.

Freire, P. (1992). Pedagogía del oprimido. Madrid: Siglo XXI.

Freire, P. (2009). La educación como práctica de la libertad. Ciudad de México: Siglo XXI.

Freire, P. (2012). Pedagogía de la indignación. Cartas pedagógicas en un mundo revuelto. Ciudad de México: Siglo XXI. 
Gadotti, M. (2000, noviembre). Pedagogy of the earth and the culture of sustainability. Comunicación presentada en Forum on our global challenges, Costa Rica 2000 commission: A new millennium of peace, University for Peace. San Jose (Costa Rica).

Galafassi, G. (2012). Entre viejos y nuevos cercamientos. La acumulación originaria y las políticas de extracción de recursos y ocupación del territorio. Revista Theomai, 26(2), 23-45.

Gilly, A. y Roux, R. (2009). Capitales, tecnologías y mundos de la vida. El despojo de los cuatro elementos. En E. Arceo y E. Basualdo (Comps.), Los condicionantes de la crisis en América Latina. Inserción internacional y modalidades de acumulación (pp. 27-52). Buenos Aires: CLACSO.

Gligo, N. (2006). Estilos de desarrollo y medio ambiente en América Latina, un cuarto de siglo después. Santiago de Chile: CEPAL

González-Casanova, P. (2003a). Colonialismo interno. Ciudad de México: IIS-UNAM.

González-Casanova, P. (2003b). Los 'Caracoles' zapatistas: Redes de resistencia y autonomía. Revista Memoria, 176(4), 14-23.

González, A. (2017). Decreto 701: El millonario bono gubernamental que financió a las grandes forestales. Recuperado de: http://www.biobiochile.cl/noticias/nacional/chile/2017/01/26/decreto701-el-millonario-bono-gubernamental-que-financio-a-las-grandes-forestales.shtml

Gramsci, A. (1971). Prison notebooks. Nueva York, NY: International Publishers.

CIDE-GTMDHAL. (2014). El impacto de la minería canadiense en América Latina y la responsabilidad de Canadá. Recuperado de http://www.dplf.org/sites/default/files/informe_canada_com

Gudynas, E. (2009). Diez tesis urgentes sobre el nuevo extractivismo: Contextos y demandas bajo el progresismo sudamericano actual. En J. Schuldt (Ed.), Extractivismo, política y sociedad (pp. 187-225). Quito: CAAP/CLAES.

Gutiérrez, F. y Prado, C. (1999). Ecopedagogia e cidadania planetaria. São Paulo: Cortez.

Harvey, D. (2003). The new imperialism. Oxford: Oxford University Press.

Harvey, D. (2005a). A brief history of neoliberalism. Oxford: Oxford University Press.

Harvey, D. (2005b). Spaces of neoliberalization: Towards a theory of uneven geographical development. Munich: Franz Steiner Verlag.

Herrera, J. F., Reyes, L., Amaya, H. O. y Gerena, O. A. (2006). Evaluación de los proyectos ambientales escolares en colegios oficiales de la localidad 18 en Bogotá. Gestión y Ambiente, $9(1), 115-122$.

Horkheimer, M. (2004). Eclipse of reason. Londres: Continuum Press

Horkheimer, M. y Adorno, T. (2002). Dialectic of enlightenment: Philosophical fragments. Los Ángeles, CA: Stanford University Press.

Hursh, D., Henderson, J. y Greenwood, D. (2015). Environmental education in a neoliberal climate. Environmental Education Research, 21(3), 299-318.

Johnston, J. (2009). Transformative environmental education: Stepping outside the curriculum box. Canadian Journal of Environmental Education, 14, 149-157.

Jutras, F. y Bertrand, Y. (1998). L'écoresponsabilité, une valeur à développer à l'école. Spirale, 21, 165-171.

Kahn, R. (2010). Critical pedagogy, ecoliteracy, and planetary crisis: The Ecopedagogy movement. Nueva York, NY: Peter Lang. 
Klein, N. (2007). The shock doctrine: The rise of disaster capitalism. Toronto: Vintage Canada.

Lamberti, M.J. (2011). Una lucha a "cielo abierto". El caso del frente amplio opositor a minera San Xavier. En H. Alimonda (Coord.), La naturaleza colonizada. Ecología política y minería en América Latina (pp. 303-331). CLACSO, Buenos Aires.

Lenoir, Y, Maubant, P., Hasni, A., Lebrun, J., Zaid, A., Habboub, E. y Mcconnel, A. C. (2007). À la recherche d'un cadre conceptuel pour analyser les pratiques d'enseignement. Sherbrooke: CRCIE.

Leff, E. (2004). Racionalidad ambiental. La reapropiación social de la naturaleza. Buenos Aires: Siglo XXI.

Leff, E. (2005). La geopolítica de la biodiversidad y el desarrollo sustentable. Economización del mundo, racionalidad ambiental y reapropiación social de la naturaleza. Revista OSAL, 5(17), 263-274.

Leff, E. (2006). La ecología política en América Latina. Un campo en construcción. En H. Alimonda (Comp.), Los tormentos de la materia. Aportes para una ecología política latinoamericana (pp. 2139). Buenos Aires: CLACSO.

Leff, E. (Ed.). (2001). Justicia ambiental: Construcción y defensa de los nuevos derechos ambientales, culturales y colectivos en América Latina. Ciudad de México: PNUD-UNAM.

Lucio-Villegas, E. (2015). Paulo Freire: La educación como instrumento para la justicia social. Revista Internacional de Educación para la Justicia Social, 4(1), 9-20

Martinez-Alier, J. (2014). The environmentalism of the poor. Geoforum, 54, 239-241.

McLaren, P. (2013). Seeds of resistance: Towards a revolutionary critical ecopedagogy. Socialist Studies, 9(1), 84-108.

MiningWatch Canada. (2013). Corruption, murder and Canadian mining in Mexico: The case of blackfire exploration and the Canadian embassy. Ottawa: MinningWatch.

MiningWatch Canada. (2015). Las entrañas de la complicidad canadiense: Excellon resources, la embajada de Canadá, y la violación de los derechos laborales y a la tierra en Durango, México. Ottawa: MinningWatch Canada.

Nelson, E. S. (2011). Revisiting the dialectic of environment: Nature as ideology and ethics in Adorno and the Frankfurt school. Telos, 155, 105-126.

Pickett, A. (2016). Theorizing transformative education: An exploration into marcuse's aesthetic dimension. Recuperado de: http://newprairiepress.org/cgi/viewcontent.cgi?article=1063\&context=aerc

PNUD. (2016). Rapport sur le développement humain 2016. París: PNUD.

Prebisch, R. (1980). Biósfera y desarrollo. En O. Sunkel y N. Gligo (Comps.), Estilos de desarrollo y medio ambiente en la América Latina (pp. 67-90). Ciudad de México: Fondo de Cultura Económica.

Rangel, M. (2004). Género, etnicidad, pobreza y mercado de trabajo en Bolivia, Ecuador, Guatemala y Perú. En M. Valenzuela y M. Rangel (Eds.), Desigualdades entrecruzadas Pobreza, género, etnia y raza en América Latina (pp. 29-86). Santiago de Chile: OIT.

Roberts, J. T. y Thanos, N. D. (2003). Trouble in paradise: Globalization and environmental crisis in Latin America. Nueva York, NY: Routledge.

Romero, P. (2011). Minería, agroindustria y agricultura tradicional, conflictos socioambientales en el semiárido chileno, el caso de la comuna de Alto del Carmen. En H. Alimonda (Coord.), La naturaleza colonizada. Ecología política y minería en América Latina (pp. 285-301). Buenos Aires: CLACSO. 
Sauma, P. (2004). Guatemala: Desigualdades étnicas y de género en el mercado de trabajo. En M. Valenzuela y M. Rangel (Eds.), Desigualdades entrecruzadas, pobreza, género, etnia y raza en América Latina (pp. 139-171). Santiago de Chile: OIT.

Sauvé, L. (1997). L’approche critique en éducation relative à l'environnement: origines théoriques et applications à la formation des enseignants. Revue des Sciences de L'éducation, 23(1), 169187.

Sauvé, L. (2007). L'équivoque du développement durable. Chemin de Traverse, 4, 31-47.

Sauvé, L. (2014). Educación ambiental y ecociudadania. Dimensiones claves de un proyecto político-pedagógico. Revista Científica, 1(18), 12-23.

Schlosberg, D. (2013). Theorising environmental justice: The expanding sphere of a discourse. Environmental Politics, 22(1), 37-55.

Seoane, J. (2005). Movimientos sociales y recursos naturales en América Latina: Resistencias al neoliberalismo, configuración de alternativas. Revista OSAL, 5(17), 93-108.

Seoane, J. (2013a). El agua vale más que el oro. La megaminería a cielo abierto. En J. Seoane, E. Taddei y C. Algranati (Coords.), Extractivismo, despojo y crisis climática. Desafíos para los movimientos sociales y los proyectos emancipatorios de Nuestra América (pp. 131-156). Buenos Aires: Ediciones Herramienta.

Seoane, J. (2013b). Modelo extractivo y acumulación por despojo. En J. Seoane, E. Taddei y C. Algranati (Coords.), Extractivismo, despojo y crisis climática. Desafís para los movimientos sociales y los proyectos emancipatorios de nuestra América (pp. 21-40). Buenos Aires: Ediciones Herramienta.

Seoane, J. y Algranati, C. (2013a). El sabor amargo del crecimiento económico: la expansión del modelo extractivo entre 2003 y 2007. En J. Seoane, E. Taddei y C. Algranati (Coords.), Extractivismo, despojo y crisis climática. Desafíos para los movimientos sociales y los proyectos emancipatorios de nuestra América (pp. 61-82). Buenos Aires: Ediciones Herramienta.

Seoane, J. y Algranati, C. (2013b). Disputas socioambientales: cambios y continuidades en la conflictividad social en América Latina. En J. Seoane, E. Taddei y C. Algranati (Coords.), Extractivismo, despojo y crisis climática. Desafíos para los movimientos sociales y los proyectos emancipatorios de Nuestra América (pp. 41-60). Buenos Aires: Ediciones Herramienta.

Simpson, L. B. y Klein, N. (2013). Dancing the world into being: A conversation with idle no more's Leanne Betasamosake Simpson. Recuperado de: http://www.yesmagazine.org/peacejustice/dancing-the-world-into-being-a-conversation-with-idle-no-more-leanne-simpson

Sunkel, O. (1980). Introducción: la interacción entre los estilos de desarrollo y el medio ambiente en la América Latina. En O. Sunkel y N. Gligo (Comps.), Estilos de desarrollo y medio ambiente en la América Latina (pp. 9-64). Ciudad de México: Fondo de Cultura Económica.

Sunkel, O. (1990). El difícil contexto internacional para un desarrollo sustentable. En G. Maihold y V. Urquidi (Comps.) Diálogo con nuestro futuro común: Perspectivas latinoamericanas del Informe Brundtland (pp. 103-129). Ciudad de México: Fundación Friedrich Ebert-Editorial Nueva Sociedad.

Sunkel, O. y Gligo, N. (Comps.). (1980). Estilos de desarrollo y medio ambiente en América Latina. Ciudad de México: Fondo de Cultura Económica.

Tabra, M. y Aste, J. (2011). Minería y territorio en el Perú: Casos, temas y propuestas. En H. Alimonda (Coord.), La naturaleza colonizada. Ecología política y minería en América Latina (pp. 223-234). Buenos Aires: CLACSO. 
Taddei, E. (2013a). Las guerras por el agua. En J. Seoane, E. Taddei y C. Algranati (Coords.), Extractivismo, despojo y crisis climática. Desafios para los movimientos sociales y los proyectos emancipatorios de nuestra América (pp. 109-130). Buenos Aires: Ediciones Herramienta.

Taddei, E. (2013b). Redes y articulaciones en defensa de los bienes comunes naturales: las coordinaciones continentales internacionales de movimientos sociales. En: J. Seoane, E. Taddei y C. Algranati (Coords.), Extractivismo, despojo y crisis climática. Desafios para los movimientos sociales y los proyectos emancipatorios de nuestra América (pp. 211-238). Buenos Aires: Ediciones Herramienta.

Thésée, G. y Carr, P. R. (2008). Une proposition d'élargissement de la dimension critique en éducation relative à l'environnement: La résistance éco-épistémologique. RegardsRecherches-Réflexions, 7, 65-90.

Thésée, G., Carr, P. R. y Potwora, F. (2015). Le rôle des enseignants dans l'éducation et la démocratie: Impacts d'un projet de recherche sur la perception de futurs enseignants. Revue des Sciences de l'éducation de McGill, 50(2), 363-387.

Valenzuela, M. E. y Rangel, M. (2004). Introducción. En M. Valenzuela y M. Rangel (Eds.), Desigualdades entrecruzadas. Pobreza, género, etnia y raza en América Latina (pp. 13-27). Santiago de Chile: OIT.

Wagner, L. y Giraud, M. (2011). El proyecto minero Potasio Río Colorado: conflicto socioambiental, impactos regionales y falta de integralidad en la evaluación ambiental. En H. Alimonda (Coord.), La naturaleza colonizada. Ecología política y minería en América Latina (pp. 257-284). Buenos Aires: CLACSO.

\section{Breve CV de los autores}

\section{Paul R. Carr}

Sociólogo, profesor titular en el Departamento de Educación de la Universidad de Quebec en Outaouais (Canadá) y titular de la Cátedra UNESCO en democracia, ciudadanía mundial y educación transformadora (DCMÉT). Sus intereses de investigación incluyen la sociología política, la interculturalidad, la democracia, la educación transformadora, la alfabetización de los medios de comunicación, y los estudios sobre la paz. Él es el investigador principal de dos proyectos de investigación: Democracia, Alfabetización Política y Educación Transformadora y Medias sociales, participación ciudadanía y educación, los cuales son subvencionado por el Consejo de Investigación de Ciencias Sociales y Humanidades de Canadá (SSHRC). ORCID ID: 0000-0002-3841-0086. Email: pcarr@gmail.com

\section{Eloy Rivas}

Candidato a Doctor en Sociología con especialización en Economía Política por la Universidad de Carleton (Canadá) e Instructor en el Departamento de Sociología y Antropología de la misma Universidad. También es Co-Coordinador de la Cátedra UNESCO en democracia, ciudadanía mundial y educación transformadora (DCMÉT). Es egresado de la primera generación de estudiantes de la Escuelita Zapatista 'Hacia la Libertad' (Generación 2014) y colabora con organizaciones sociales que promueven la democracia, los derechos de las comunidades indígenas y los derechos de los migrantes tanto en Canadá como en América Latina. ORCID ID: 0000-0002-3482-1478. Email: eloyrivassanchez@cmail.carleton.ca 


\section{Nancy Molano}

Máster en Ciencias biológicas-ecología y licenciada en Biología de la Universidad Pedagógica Nacional de Colombia. Estudiante del doctorado en educación de la Universidad de Québec en Montréal (UQAM). Dentro de sus intereses de investigación se encuentran la educación ambiental, la educación en la escuela y la didáctica de las ciencias en contextos vulnerables en América Latina. ORCID ID: 0000-0003-1953-4101. Email: nayamoni@gmail.com

\section{Gina Thésée}

Profesora titular en el Departamento de Educación de la Universidad de Quebec en Montreal (UQAM) y Co-Titular de la Cátedra UNESCO en democracia, ciudadanía mundial y educación transformadora (DCMÉT). Participa de forma regular en actividades de la International Task Force on Teachers for Education 2030 (UNESCO). Sus intereses de investigación son los contextos socioeducativos en relación con temas de colonización, cultura, etnicidad, género y raza. Antes de entrar en la academia, ella fue maestra de educación básica. Ella es co-investigadora de dos proyectos de investigación: Democracia, Alfabetización Política y Educación Transformadora y Medias sociales, participación ciudadanía y educación, los cuales son subvencionado por el Consejo de Investigación de Ciencias Sociales y Humanidades de Canadá (SSHRC). ORCID ID: 0000-0002-2433-8781. Email: thesee.gina@uqam.ca 